\title{
Tipos e Dinâmicas de Mudança Institucional: As Agências Reguladoras de Transportes no Brasil*
}

\author{
Alexandre de Ávila Gomide
}

Integrante da carreira de Pesquisa e Planejamento do Instituto de Pesquisa Econômica Aplicada (Ipea). Brasília, DF, Brasil. E-mail: alexandre.gomide@ipea.gov.br

\section{INTRODUÇÃO}

R eformas institucionais ocorreram no Brasil em diversos setores 1 durante a década de 1990, especialmente nos serviços de infraestrutura. No entanto, tais mudanças aconteceram sob diferentes padrões e uma variedade de configurações institucionais surgiu como resultado. Como notou Menardi (2004), as trajetórias históricas de construção dos diferentes setores, de suas empresas, autarquias e ministérios, mostram que não se pode entender como único o processo de reforma regulatória ocorrido no Brasil dos anos 1990: as instituições preexistentes, as bases econômicas e as coalizões políticas de cada setor são distintas. Por isso, uma mesma direção comum de reforma mostrou diferentes resultados.

O caso do setor federal de transportes, objeto deste artigo, é elucidativo. Neste, os processos de desestatização, liberalização e descentralização iniciaram-se no final da década de 1980, mas a reestruturação regulatória dos serviços somente aconteceu mais de dez anos depois,

\footnotetext{
* Este artigo é baseado na minha tese de doutorado intitulada, A Política das Reformas Institucionais no Brasil: A Reestruturação do Setor de Transportes, defendida em 2011, no programa de Administração Pública e Governo da Escola de Administração de Empresas de São Paulo, da Fundação Getulio Vargas.
}

DADOS - Revista de Ciências Sociais, Rio de Janeiro, vol. 57, no-3, 2014, pp. 855 a 885. 
com a promulgação da Lei Federal no 10.233/2001, que criou, dentre outras organizações, duas agências reguladoras autônomas vinculadas ao ministério setorial: uma para os transportes terrestres (rodoviário e ferroviário) e outra para o transporte aquaviário (navegação e portos).

Este artigo objetiva explicar o processo que resultou na configuração institucional do setor federal de transportes consubstanciado na citada lei federal. Especificamente, identificar as causas e os mecanismos que resultaram na divisão das competências regulatórias do Ministério dos Transportes em duas agências reguladoras em vez de uma, como era a intenção inicial do Poder Executivo. Justifica-se a escolha do setor como caso de estudo pela sua relevância para a infraestrutura nacional e pelo fato de o mesmo ter sido ainda pouco analisado, no que se refere aos processos políticos que resultaram nas suas transformações institucionais mais recentes ${ }^{1}$.

Por incorporar variáveis político-institucionais à análise e preocupar-se em mostrar como o processo de reforma em questão foi marcado pelas instituições preexistentes, este artigo pretende contribuir para o programa de pesquisa do Institucionalismo Histórico da Ciência Política contemporânea. Assim sendo, o trabalho não se concentra no impacto das reformas em termos de resultados setoriais (por exemplo, sobre a oferta dos serviços ou a atração de investimentos privados), tampouco avalia o desempenho das agências reguladoras criadas: o foco é exclusivamente processual. Parte-se do pressuposto de que as instituições e seus processos de mudança têm valor intrínseco, constituindo-se, em si mesmas, importantes objetos de estudo.

O artigo divide-se em quatro seções, além desta introdução. A seguir, apresentam-se a abordagem teórica e a metodologia de pesquisa empregada. Na seção seguinte, é reconstituído o processo político que resultou na Lei no 10.233 / 2001 que, entre outras disposições, criou as novas organizações do setor. Em seguida, reconstrói-se a interpretação causal para o fenômeno em estudo, mobilizando a abordagem teórica anteriormente apresentada. Por fim, à guisa de conclusão, a última seção expõe as implicações teórico-conceituais proporcionadas pela análise.

\section{A ABORDAGEM TEÓRICA}

Segundo Pierson (2006), a análise institucionalista-histórica é baseada em alguns pressupostos básicos: que os processos políticos podem ser 
melhor compreendidos se forem estudados ao longo do tempo; que as instituições, especialmente aquelas que emanam do Estado, são fontes importantes do comportamento político; e que a investigação detalhada de casos cuidadosamente escolhidos é uma ferramenta poderosa para descobrir fontes de mudança política. De tal modo, o institucionalismo histórico se caracteriza em relação às demais escolas institucionalistas por trabalhar com a ação individual de forma integrada aos fatores estruturais (Hall e Taylor, 2003; Thelen, 1999). Para os autores desta abordagem teórica, o comportamento dos atores políticos é constrangido por processos históricos cristalizados em conjuntos específicos de instituições. Ou seja, as instituições oferecem o contexto em que os indivíduos moldam seus interesses e definem suas preferências, conformando as políticas públicas.

Da mesma maneira, os teóricos da vertente histórica do institucionalismo referem o conflito de interesses entre grupos rivais e as relações desiguais de poder como centrais à vida política. Por isso, as instituições não são mecanismos neutros de coordenação, que sustentam uma ordem em equilíbrio e exógenas ao comportamento dos indivíduos. Ao contrário, são resultado de processos complexos, marcadas pelo conflito e pela contingência na luta pelo poder que, por apresentarem implicações distributivas, trazem consigo uma permanente tensão (Mahoney e Thelen, 2010).

São muitas as definições de "instituições" adotadas pelas escolas institucionalistas das diferentes disciplinas (ciência política, economia, sociologia etc.), que tanto podem transportar o conceito para níveis mais abstratos, interpenetrando as instituições com a cultura, quanto para níveis mais circunscritos, como as regras formais. Ao examinar as diferentes definições adotadas, Scott (2008) identifica três elementos "cultural-cognitivos", "normativos" e "regulativos" - que formam um continuum que vai dos aspectos inconscientes para os conscientes das instituições (ou dos "tidos como certos" para os legalmente garantidos). A ênfase em cada um desses elementos, conforme o autor, vai depender da ontologia de cada uma das abordagens teóricas (isto é, das diferentes visões sobre a natureza da realidade e das relações causais que elas assumem). Os elementos cultural-cognitivos envolvem as crenças comuns, os scripts coletivos, as rotinas e os hábitos sociais. Os normativos incluem os valores e as normas (no sentido de como as coisas deveriam ser). Por sua vez, os elementos regulativos compreendem as regras formais (leis, regulamentos etc.) e informais (costumes, tradi- 
ções etc.) que limitam e regularizam o comportamento dos atores. Levando em consideração a abordagem do institucionalismo histórico de Pierson (2004) e Mahoney e Thelen (2010), o conceito de instituições adotado neste artigo priorizará os atributos regulativos das mesmas, sobretudo seus elementos formais, ou seja, as regras e procedimentos formais estabelecidos pela ação dos governos e mantida (enforced) pelo poder coercitivo do Estado².

Uma questão em aberto nesta abordagem é a mudança institucional. Pierson (2004) afirma que as instituições não são "plásticas", ou seja, elas não aceitam incondicionalmente iniciativas de reformas. Dessa maneira, ele vai buscar elementos analíticos para explicar os mecanismos que elucidam a resiliência das instituições. Em Pierson, tal resposta está no mecanismo de path dependence. Grosso modo, este mecanismo baseia-se na noção de que uma vez iniciada uma trajetória (um processo político), os custos de reversão desta se tornam cada vez mais altos com o passar do tempo ${ }^{3}$. Por isso, em uma sequência de eventos, as últimas decisões não são (inteiramente) independentes das que já ocorreram, ou seja as decisões do passado restringem as escolhas do presente. Deste modo, as análises podem recorrer ao mecanismo para sustentar hipóteses que afirmam, entre outras, que o resultado alcançado de um processo em curso pode não ser o mais eficiente ${ }^{4}$.

No entanto, o uso do conceito de path dependence pode levar a uma interpretação determinística do mecanismo, que levaria a situações de lock-in capazes de serem superadas apenas por meio de "choques exógenos" ou "conjunturas críticas" ${ }^{5}$. Por isto, alguns autores propõem-se a trabalhar com padrões de mudanças institucionais alternativos aos modelos de "equilíbrio pontuado", nos quais os longos períodos de estabilidade institucional seriam interrompidos por momentos de mudanças concentradas (transformações radicais, promovidas por fatores exógenos), seguidas por novo período de estabilidade até que uma nova conjunção crítica ocorra (cf. Baumgartner e Jones, 1993).

É neste sentido que aparece o modelo de mudança endógena de Mahoney e Thelen (2010). Estes autores apresentam uma tipologia de mudança institucional na forma de quatro modos básicos: (i) displacement, ou remoção das antigas instituições com a introdução de novas; (ii) layering, ou a introdução de novas instituições sobre as existentes; (iii) drift, ou modificação do impacto das instituições vigentes devido a transformações no ambiente; e (iv) conversion, ou a conversão de uma 
instituição existente para novos objetivos. Enquanto o primeiro modo (displacement) conformaria uma mudança radical ou fundamental na instituição em questão, os três últimos acomodariam mudanças incrementais. Para Mahoney e Thelen (idem), o entendimento desses diferentes tipos de mudança seria precondição para explicar "como" e "por que" mudanças institucionais ocorrem.

Segundo os autores citados, três fatores explicariam os tipos de mudança apresentados: o contexto político; as características da instituição preexistente; e os atributos dos atores dominantes. O contexto político está ligado à distribuição de poder. O sucesso da tentativa de mudar uma instituição depende do poder de veto dos defensores do status quo. Ou seja, quanto mais forte o poder de veto dos opositores à mudança, menor a probabilidade de acontecerem transformações numa instituição. A característica da instituição, por sua vez, está relacionada à discricionariedade na interpretação ou aplicação das regras existentes. Para Mahoney e Thelen (idem), as instituições têm sistemas formais de codificação (uma lei, por exemplo), sendo que algumas regras podem não ter sido definidas claramente, abrindo a possibilidade para contestações ou interpretações diferentes quanto aos seus objetivos ou aplicação de seus instrumentos, por exemplo. Esta situação pode ser explorada por atores interessados na mudança. Finalmente, os atores dominantes são os agentes da mudança institucional. Mahoney e Thelen (idem) definem tais atores de acordo com o desejo dos mesmos de preservar e cumprir as regras, perfazendo quatro tipos: (i) os insurgentes, que rejeitam o status quo institucional; (ii) os simbiontes, que desejam preservar e explorar o status quo, aplicando as regras conforme seus interesses; (iii) os subversivos, que procuram mudar a instituição, mas sem confrontar as regras existentes; e (iv) os oportunistas, que ao explorar as ambiguidades das regras em vigor, acabam por reinterpretar os objetivos das mesmas de forma diferente à intenção de seus formuladores.

Assim, residiriam nas características das estruturas (instituição e contexto político) e dos atores a explicação para os diferentes tipos de mudança institucional. O Quadro 1 resume a tipologia de Mahoney e Thelen (idem). Destaque-se que a mesma deve ser entendida como um recurso heurístico no auxílio à apreensão intelectual de fenômenos empíricos. 


\section{Quadro 1}

Estrutura, Atores e Tipos de Mudança Institucional

\begin{tabular}{|c|c|c|c|}
\hline & \multicolumn{2}{|c|}{ Característica da Instituição Preexistente } \\
\hline & & $\begin{array}{c}\text { Baixa } \\
\text { discricionariedade na } \\
\text { interpretação ou } \\
\text { aplicação das regras }\end{array}$ & $\begin{array}{c}\text { Alta } \\
\text { discricionariedade na } \\
\text { interpretação ou } \\
\text { aplicação das regras }\end{array}$ \\
\hline \multirow{2}{*}{ Contexto político } & $\begin{array}{c}\text { Forte poder de } \\
\text { veto dos opositores }\end{array}$ & $\begin{array}{c}\text { Layering } \\
\text { (subversivos) }\end{array}$ & $\begin{array}{c}\text { Drift } \\
\text { (simbiontes) }\end{array}$ \\
\hline & $\begin{array}{c}\text { Fraco poder de } \\
\text { veto dos opositores }\end{array}$ & $\begin{array}{l}\text { Displacement } \\
\text { (insurgentes) }\end{array}$ & $\begin{array}{c}\text { Conversion } \\
\text { (oportunistas) }\end{array}$ \\
\hline
\end{tabular}

Fonte: Mahoney e Thelen (idem:19).

Para Pierson (2006), as políticas públicas também podem ser tomadas como instituições, pois elas estabelecem regras que moldam o comportamento dos atores (quem eles são, o que eles querem ou como e com quem eles se organizam). Assim, as políticas públicas impactam no desenvolvimento dos processos políticos ao longo do tempo ${ }^{6}$. Do mesmo modo como ocorre com a dinâmica institucional, argumenta o citado autor, os custos da mudança de uma política pública para outra aumentam com o passar do tempo. O mecanismo de policy feedback explicaria esse fenômeno: os atores têm interesses na manutenção de uma determinada política, mas foi a política implementada que moldou os interesses desses atores.

Da mesma forma, escreve Pierson (1993:600; tradução livre), “uma política pública não só fornece incentivos para os que são favoráveis a ela: ela pode também alimentar mobilizações contrárias, envolvendo novas formas de organização política". Ou seja, a implementação de políticas públicas pode impulsionar novas formas de organização para modificar a política em curso, criando nichos e incentivos para que empreendedores políticos possam superar problemas de ação coletiva ${ }^{7}$. Assim, se para certas abordagens a ação dos grupos (por exemplo, via lobby) determina a produção de políticas públicas, para o institucionalismo histórico esta direção causal pode ser invertida: em muitos casos, as políticas públicas vêm em primeiro lugar, fornecendo as bases para a formação de padrões específicos de ação política.

O que se estabelece como desafio, afinal, é aplicar essas formulações por meio da pesquisa empírica. No caso, converter tais conceituações e proposições teóricas em instrumentos para análise de um problema concreto de pesquisa. Nesse objetivo, utilizou-se da técnica de rastrea- 
mento de processos, ou process tracing (George e Bennett, 2004) para reconstituir os nexos causais que culminaram na reestruturação institucional do setor federal de transportes, com a criação da Agência Nacional de Transportes Terrestres (ANTT) e da Agência Nacional de Transportes Aquaviários (Antaq), objeto da seção seguinte ${ }^{8}$.

\section{O PROCESSO POLÍTICO}

Esta seção reconstitui o processo de discussão e aprovação da nova legislação no Congresso Nacional, identificando os diversos atores e respectivos interesses envolvidos, bem como as coalizões que se construíram a partir da dinâmica de atuação das mesmas. Entendeu-se o Congresso como o lugar ideal para analisar a dinâmica do processo, dado que o setor de transportes é subdividido em modalidades e envolve um mosaico de atores e interesses. Desta maneira, a Comissão Especial da Câmara dos Deputados destinada a examinar o Projeto de Lei do Executivo de reestruturação institucional do setor constituiu-se na principal arena de negociação entre o Poder Executivo, parlamentares e os grupos de interesse. Para Velasco Jr. (2005:46), as comissões do Congresso são o lócus de expressão dos interesses por excelência, por conta da identificação dos parlamentares que nela atuam em relação à matéria a ser apreciada, o que de alguma forma os vincula a setores econômico-sociais específicos. Conforme o autor, é durante a negociação de uma proposição legislativa numa Comissão do Congresso que o Executivo e sua coalizão legislativa são informados sobre os interesses em jogo, por meio do mecanismo que a literatura tem denominado de "alarme de incêndio". Tais interesses são, por sua vez, mediados pelo relator da matéria, que tem papel fundamental, já que cabe a ele apresentar o projeto substitutivo ao original, incorporando as propostas dos parlamentares e, por conseguinte, os interesses dos demais atores.

Em setembro de 1999, o Poder Executivo encaminhou ao Congresso Nacional mensagem submetendo projeto de lei que dispunha sobre a criação da Agência Nacional de Transportes (ANT), entre outras providências. Na Câmara dos Deputados, o projeto recebeu a denominação PL-1.615/1999. Na exposição de motivos da Mensagem Presidencial, constava a intenção de se estabelecer os lineamentos para o novo papel do Estado em sua função reguladora, completando, assim, as reformas no setor de transportes em curso no Brasil desde o início da década de 1990 por meio da delegação de poderes regulatórios do ministério setorial para uma agência autônoma. 
A ANT, aos moldes das outras agências já criadas (por exemplo, a Agência Nacional de Telecomunicações - Anatel), seria uma autarquia especial vinculada, mas não subordinada, ao Ministério dos Transportes, desempenhando, como autoridade administrativa autônoma, a função de entidade reguladora e fiscalizadora dos segmentos do sistema federal de viação sob a exploração da iniciativa privada. Conforme o Projeto de Lei, as áreas de atuação da ANT seriam: o transporte ferroviário (incluindo os ativos arrendados ao setor privado); o transporte rodoviário de passageiros; as rodovias concedidas; e a Marinha Mercante e os portos. Caberia ainda, à agência reguladora, a proposição ao Ministério dos Transportes dos planos de outorgas do que seria concedido ao setor privado, bem como as condições sob as quais essas outorgas seriam efetivadas.

O projeto previa também a criação do departamento de infraestrutura de transportes, que sucederia o Departamento Nacional de Estradas de Rodagem (DNER), como uma autarquia subordinada ao Ministério dos Transportes, na forma de um órgão executivo de investimento em infraestrutura rodoviária, ferroviária, hidroviária e portuária. Tal departamento não teria independência administrativa e financeira (isto é, contaria com recursos da União) e desempenharia funções relativas à construção, manutenção e operação da infraestrutura dos segmentos do sistema federal de viação sob a administração direta do governo federal. Seus objetivos, por conseguinte, seriam operar e administrar a infraestrutura de transportes, gerir projetos de infraestrutura e supervisionar e fiscalizar as atividades de entidades delegatórias de obras e serviços.

Destaque-se, portanto, que a proposta inicial do Executivo previa um desenho institucional que contaria com a criação de uma única agência reguladora para os transportes sob o pressuposto de que a aglutinação da regulação das modalidades rodoviárias, ferroviárias e aquaviárias numa só agência traria benefícios em relação à tomada de decisão, visando a articulação entre os diferentes modos de transporte sob o enfoque da multimodalidade.

Na Câmara dos Deputados foi criada uma Comissão Especial (Cesp) destinada a proferir parecer ao projeto de lei do Executivo. Como relator da Cesp para discutir o projeto de lei em questão foi designado o então deputado Eliseu Resende (PFL-MG), que possuía longa trajetória no setor de transportes, tendo sido diretor-geral do Departamento de 
Estradas de Rodagem de Minas Gerais (DER-MG), diretor-geral do DNER e ministro dos Transportes entre os anos de 1979 e 1982. No Congresso, como deputado federal no período de 1995 a 2002, teve papel atuante nos processos de reforma do Estado, relatando a lei que quebrou o monopólio do petróleo e criou a ANP (Agência Nacional do Petróleo, Lei 9.478 /1997) e também a lei que estabeleceu o Sistema Nacional de Recursos Hídricos, e criou a Agência Nacional de Águas (Lei 9.984/2000).

Em seus trabalhos, a Cesp do PL-1.615/1999 realizou 25 reuniões, sendo que 16 delas tiveram caráter de audiência pública. Nestas, foram ouvidos os diferentes atores ligados ao setor, entre empresários, trabalhadores, especialistas e representantes de esferas de governo. Vários pontos do projeto de lei do Executivo foram objeto de controvérsia e discussão nos trabalhos da Comissão. Entre eles se destacou o fato de o subsetor aeroviário não ter sido incluído no projeto do Executivo, tanto no que se refere às concessões das linhas aéreas quanto na condução da administração aeroportuária. Neste sentido, vale a pena transcrever a posição do então deputado Alberto Goldman (PSDB-SP) sobre esse assunto:

Gostaria de fazer algumas observações. Em primeiro lugar, algo com que todos vão concordar: de uma vez por todas, ou assumimos ou dizemos que somos suficientemente fracos para não assumir. Não há nenhuma razão para que o setor aeroviário, o setor de aeroportos não esteja incluído no setor de transportes. [...] Acho que estamos fazendo uma coisa séria aqui - e é assim que temos que fazê-la - e não há como não discutirmos a questão da infraestrutura aeroportuária. É tão importante quanto qualquer outro desses setores. Portanto, não pode ficar como uma reserva de domínio de algumas pessoas do setor público - usem ou não usem galões. Não me interessa, são funcionários públicos como quaisquer outros. Houve um tempo em que eles tinham em suas mãos algo mais do que o galão. No seu peito tinha um galão, mas em suas mãos tinha algo mais. E a sociedade se atemorizava diante disso. Não é mais a situação. Vivemos num regime democrático, e, no regime democrático, não é mais aceitável que o setor aeroportuário esteja fora de um projeto de reformulação do setor de transportes. Não consigo admitir e não consigo imaginar. E quero ver se alguém consegue dar alguma explicação [...]. Historicamente, no Brasil, temos o Departamento de Aviação Civil e a Infraero como concessionária, ligados ao que era o Ministério da Aeronáutica. Hoje, não existe mais o Ministério 
da Aeronáutica, existe o Comando da Aeronáutica e o Ministério é o da Defesa. Parece-me que se antes já ficava muito claro que era uma relação estranha, no Ministério dos Transportes sentimos isso, porque a todos os congressos a que íamos, na hora de discutir aviação, transporte aéreo, tínhamos de nos retirar da sala, porque não se tratava mais de Ministério dos Transportes; era do Ministério da Aeronáutica (Deputado Alberto Goldman, durante a 3 a reunião da Cesp, em 23/11/1999).

A respeito desta questão, conforme relatos colhidos dos atores entrevistados, o Comando da Aeronáutica havia vetado as iniciativas articuladas pelo então ministro da Defesa, Élcio Álvares, de incluir o transporte aéreo no rol de competências da ANT proposta pelo Executivo. Deste modo, sob a alegação de que a lei que definiu as atribuições das Forças Armadas vinculou a gestão da aviação civil ao Ministério da Defesa e determinou que fosse criada uma agência reguladora específica para a aviação civil ${ }^{9}$, a Cesp abandonou o assunto e a regulação da aviação civil continuou até o fim do governo Fernando Henrique Cardoso sob o controle da aeronáutica, sendo que a Agência Nacional de Aviação Civil (Anac) foi criada somente no ano de 2005, sob o governo Luíz Inácio Lula da Silva.

A proposta de extinção do Geipot (a empresa estatal responsável pelo planejamento dos transportes), decorrente da reestruturação proposta pelo Executivo, também causou preocupação a parlamentares e especialistas ouvidos pela Cesp, pois o projeto de lei não definiu a função do planejamento estratégico do setor na nova estrutura organizacional do governo federal.

Outros pontos também foram objeto de controvérsia e discussão por parte de parlamentares e grupos de interesse ligados aos subsetores de transporte (ferroviário, rodoviário de cargas e passageiros, concessionários de rodovias e empreiteiros de obras). Não obstante, foi a questão do transporte aquaviário que resultou na cisão da agência inicialmente proposta pelo Executivo em duas: uma para o transporte ferroviário e rodoviário, e outra para a navegação e portos.

As empresas de navegação nacional, representadas pelo Sindicato Nacional das Empresas de Navegação Marítima (Syndarma), expressaram o interesse que a navegação nacional, inclusive a indústria da construção naval, pudesse contar com uma agência que tratasse especificamente da atividade. Após o processo de liberalização e desregulação da navegação ocorrido no início dos anos 1990, assistiu-se tanto à 
internacionalização patrimonial dos armadores nacionais, restando diminuta frota de bandeira brasileira para garantir políticas de frete do comércio internacional, ou para assegurar o transporte de cabotagem, além da consequente desativação da indústria da construção naval nacional. Em favor da proposta de uma agência específica para a navegação, os armadores defenderam que tal organização fosse criada para dar à Marinha Mercante brasileira condições autônomas para seu desenvolvimento, agregando, inclusive, a administração do Fundo da Marinha Mercante, principal instrumento de fomento ao desenvolvimento do setor ${ }^{10}$.

Destaque-se que, em meio às entidades empresariais do transporte aquaviário, há distinção entre a atividade de transporte em si, englobando a navegação, e as atividades ligadas aos portos. Assim sendo, se havia por parte dos armadores nacionais a preferência pela criação de uma agência específica para o transporte aquaviário, os empresários vinculados aos portos tinham o interesse inicial na manutenção do status quo institucional, ou seja, que fosse mantida a estrutura regulatória do subsetor instituída pela Lei de Modernização dos Portos (Lei 8.630/1993). Esta lei implicou a descentralização da administração portuária, na qual a autoridade portuária é exercida, de forma autônoma, entre a Administração do Porto e o Conselho de Autoridade Portuária $(\mathrm{CAP})^{11}$. As entidades empresariais ligadas aos portos ${ }^{12}$ argumentavam, portanto, que a atividade portuária já disporia do agente regulador e fiscalizador. Assim sendo, a criação de uma agência reguladora para o subsetor iria, segundo eles, prejudicar o processo de modernização em curso, devido à superposição de um novo órgão, a agência reguladora, na relação entre CAPs e Administrações Portuárias. Preferiam, por conseguinte, que a nova lei evitasse qualquer menção aos portos.

Os trabalhadores marítimos, representados pelo Sindicato Nacional dos Oficiais da Marinha Mercante (Sindmar) e a Confederação Nacional dos Trabalhadores em Transportes Aquaviários e Aéreos, na Pesca e nos Portos (Conttmaf), defendiam a criação de uma agência específica para os transportes aquaviários. Tinham interesse no reerguimento da navegação nacional, pois com as transformações ocorridas na atividade a partir do início dos anos de 1990, os armadores nacionais de navios mercantes começaram a adotar uma série de procedimentos a fim de se tornarem competitivos frente à competição estrangeira que incluíam, entre outros: o corte no número de tripulantes, a diminuição do 
número de trabalhadores efetivos e o aumento do número de trabalhadores interinos (contratados por prazo determinado), por serem estes menos onerosos para as empresas (isto é, não possuem os mesmos direitos do trabalhador efetivo, como indenização por tempo de serviço, multa rescisória, férias e assistência médica). Além disso, a adoção das "bandeiras de conveniência" por parte das empresas de navegação ${ }^{13}$, como forma de minimizar custos acabou por resultar em não cumprimento das normas mínimas para trabalho marítimo estabelecidas pela Organização Internacional do Trabalho (OIT).

Já os trabalhadores portuários tinham interesse em manter as conquistas da Lei de Modernização dos Portos, de 1993. Para este grupo, essa lei seria "vocacionada à negociação", pois estabeleceu não só a gestão descentralizada como também instrumentos de relacionamento entre as autoridades portuárias, operadores privados e trabalhadores. Os CAPs, na visão dos trabalhadores portuários, se constituíam em verdadeiros fóruns de negociação e resolução de conflitos com empresários. Assim, segundo a categoria, a modificação do espírito da Lei dos Portos, que a proposta do Executivo indicava, traria prejuízos naquilo que havia sido conquistado ${ }^{14}$. Contudo, apoiavam a intenção da criação de uma agência específica para o subsetor aquaviário, pois, segundo eles, seria "preferível ter uma agência reguladora a ter o capital privado tomando conta de tudo"15.

Desse modo, acabou por consolidar-se uma coalizão de interesses entre os atores do subsetor aquaviário (trabalhadores e empresários das atividades portuárias e navegação marítima), que terminaram por incluir no texto substitutivo do relator a proposta da cisão da ANT em duas agências, a Antaq e a ANTT. Essa coalizão - que contou com o apoio tácito do Comando da Marinha do Brasil - foi vocalizada na Cesp pela deputada Jandira Feghali (PCdoB-RJ), então cônjuge do presidente da Conttmaf, a confederação à qual estão filiados todos os sindicatos marítimos e as federações de sindicatos portuários.

Como ressaltado por Ferraz et al. (2002), os atores vinculados à navegação marítima, inclusive as Forças Armadas, têm poder de influência na direção das políticas públicas para o subsetor. O Comando da Marinha do Brasil, mediante a Diretoria de Portos e Costas (DPC), é responsável pelo controle da Marinha Mercante nacional, que é considerada o braço desarmado da Marinha de Guerra. Ademais, cabe à Marinha do Brasil a formação do pessoal marítimo, inclusive dos oficiais da Mari- 
nha Mercante. Segundo Fadda (1999), a doutrina militar de defesa nacional considera estratégica para o país a construção naval e a Marinha Mercante. Daí a preocupação do Comando da Marinha com a debilidade da Marinha Mercante e a indústria naval brasileira e o apoio ao movimento em prol da criação de uma agência específica para a atividade. Ademais, é desnecessário relevar a perda de poder que implicaria ao DPC a criação de uma agência reguladora única, aglutinando todas as modalidades de transportes, como proposto inicialmente pelo Executivo. Contudo, por questões de hierarquia militar, o DPC não podia trabalhar explicitamente como ator interessado no processo de discussão no Congresso - o que não impediu que esse ator tivesse papel fundamental ao pôr em ação uma coalizão em prol da criação de uma agência específica, dedicada ao transporte aquaviário.

Já em relação à deputada Jandira Feghali, ela, além de ser, à época, cônjuge do oficial da Marinha Mercante e presidente da Conttmaf, compartilhava dos objetivos de caráter nacionalista dos militares de soerguer a navegação e a indústria de construção naval nacional. Ademais, tinha interesse na ampliação e consolidação de suas bases eleitorais e redes de apoio, incluindo recursos para financiamento de campanhas ${ }^{16}$. Dessa maneira, a deputada foi autora da emenda que propôs a substituição global do texto enviado pelo Executivo com a criação de uma agência específica para o transporte aquaviário, acatada parcialmente pelo relator da Cesp. Conforme a emenda apresentada, tal agência iria além das funções reguladoras (fixação de tarifas, outorga de autorizações para empresas e fiscalização da atividade), incluindo incumbências de fomento da atividade, mediante a administração do Fundo de Marinha Mercante. A ideia implícita era recriar a Superintendência Nacional da Marinha Mercante (Sunamam), autarquia que planejava, coordenava, e controlava o transporte aquaviário até 1989. Quanto aos serviços portuários, a proposta apresentada pela deputada reservava às autoridades portuárias (Administrações Portuárias e CAPs) a competência de regulação das áreas sob exploração comercial, idêntica à Lei 8.630/1993, sendo que somente os portos organizados (públicos) a serem concedidos à iniciativa privada seriam objeto de regulação da nova agência.

Dessa maneira, o substitutivo apresentado pelo relator da Cesp, deputado Eliseu Resende, acabou por modificar e ampliar o conteúdo da proposição inicial enviada pelo Executivo. Além de cindir a Agência Nacional de Transportes em duas, a Antaq e a ANTT, criou mais um ór- 
gão, o Conselho Nacional de Integração de Políticas de Transporte (Conit). A criação do conselho foi justificada pela necessidade de se propiciar a coordenação e a integração das políticas dos diferentes subsetores, já que agora o setor federal de transportes ficaria com três agências: duas vinculadas ao Ministério dos Transportes e outra (para o transporte aéreo, a ser criada) ao Ministério da Defesa.

Ao apresentar seu substitutivo, o relator da matéria assim justificou sua proposta de criação de uma agência específica para o transporte aquaviário:

Houve atuação forte do setor ligado à navegação, assim como discussão e debate interno entre ministros de Estado. Finalmente, em um entendimento com o Poder Executivo, na delineação exata das atribuições, foi o relator levado à condição de propor a criação de duas agências vinculadas ao Ministério dos Transportes: Agência Nacional de Transportes Terrestres, que cuidará do transporte rodoviário e ferroviário, e Agência Nacional de Transportes Aquaviários (Deputado Eliseu Resende, na 22aㅡ reunião da Cesp, em 24/5/2000).

Como se observa, a decisão de cindir a ANT em ANTT e Antaq foi resultado do processo político de articulação dos interesses dos atores no Congresso. A adesão tácita do Comando da Marinha à proposta de cisão das agências foi fundamental para o resultado final do processo final, pois, ao que consta, nem o ministro dos Transportes do período, nem o relator da Cesp eram favoráveis à criação de uma agência específica para o transporte aquaviário.

Após passar pela Câmara dos Deputados, a matéria foi apreciada pelo Senado Federal em regime de urgência e aprovado em abril de 2001, sem alterações. Collyer (2008:135) relata que no Senado foi firmado um compromisso entre a Associação Brasileira dos Terminais Portuários (ABTP) e o Poder Executivo no sentido de a futura Agência Nacional de Transportes Aquaviários respeitar as disposições da Lei dos Portos, que regulavam os contratos de arrendamento e de adesão dos terminais privativos, bem como manter as atribuições, competências e formas de atuação dos CAPs.

Encaminhado ao Executivo, o projeto foi sancionado em 5 de junho do mesmo ano, com vetos parciais. Entre eles, destacam-se: a suspensão da criação de uma estrutura de planejamento no Ministério dos Transportes, que incorporaria as atribuições de planejamento e pesquisa do 
extinto Geipot e prestaria assessoramento técnico ao Conit; e veto ao dispositivo que instituía conselhos de caráter consultivo às agências, composto por representantes do governo, usuários, operadores e trabalhadores.

Em relação ao funcionamento das novas organizações, a ANTT e a Antaq tiveram sua constituição efetiva apenas em 2002 - último ano do segundo mandato do presidente Cardoso. O Conit, por sua vez, sequer chegou a ser implementado por aquele governo ${ }^{17}$. Como primeiro diretor-geral da ANTT foi nomeado José Alexandre Nogueira Resende, filho do relator da Lei 10.233/2001, o deputado Eliseu Resende. Para diretor-geral da Antaq, foi indicado Carlos Alberto Wanderley Nóbrega, ex-presidente do Geipot e coordenador da comissão do Ministério dos Transportes que formulou o projeto de lei do Executivo. Apesar de ter sido criado para construir toda a infraestrutura viária federal (hidrovias, ferrovias e rodovias), o Departamento Nacional de Infraestrutura de Transportes (Dnit), órgão que veio a substituir o antigo DNER, continuou a ser essencialmente um órgão de construção e manutenção da infraestrutura rodoviária. Contribuiu para isso a não extinção da Valec S.A., empresa pública de construção de ferrovias vinculada ao Ministério dos Transportes, bem como a pequena parcela dos recursos destinados às hidrovias ${ }^{18}$.

Deste modo, a Lei 10.233/2001 delineou uma nova estrutura institucional do setor federal de transportes, ao atribuir: (i) a função de regulação dos serviços públicos delegados às empresas privadas à ANTT e à Antaq; (ii) a responsabilidade pela execução das atividades mantidas no âmbito público (não delegadas) ao Dnit; e (iii) a definição da política e planejamento estratégico tanto ao Ministério dos Transportes como ao Conit. Esquematicamente, o desenho organizacional propugnado pela Lei 10.233/2001 pode ser representado pela Figura 1.

Destaque-se que as novas agências herdaram a administração de contratos dos quais não haviam participado do processo de formulação. Muitos deles, inclusive, foram firmados em caráter quase que emergencial (como o caso das ferrovias arrendadas). Do mesmo modo, tiveram que atuar num modelo de arrendamentos e autorizações de terminais portuários para a iniciativa privada que foram estabelecidos antes mesmo da Lei das Concessões, de 1995 (caso dos portos). Tais fatos acentuaram as dificuldades de ação regulatória efetiva por parte das agências. 
Figura 1

Estrutura Organizacional do Setor Federal de Transportes

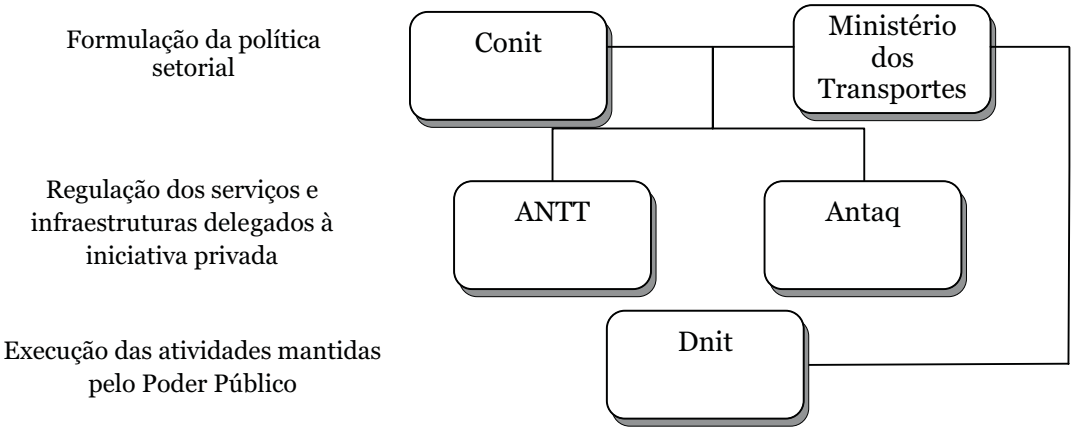

Fonte: Elaboração do autor, com base na Lei nํㅗ 10.233/2001.

\section{INTERPRETAÇÃO CAUSAL}

Nesta seção reconstrói-se a interpretação causal para o fenômeno em análise utilizando-se da abordagem teórica apresentada anteriormente. Com isto, busca-se responder às questões que nortearam o caso em tela.

O processo de reforma no setor federal de transportes começou ainda no governo Fernando Collor, por meio dos programas de desestatização e desregulamentação (respectivamente, a Lei 8.031 e o Decreto 99.179, ambos de 1990). No setor ferroviário, a Rede Ferroviária Federal (RFFSA) foi incluída no Programa Nacional de Desestatização (PND) por medida provisória, em 1992. Neste ano também foram extintos os monopólios regionais na aviação civil, iniciando o processo de flexibilização da entrada de novas empresas no mercado e de liberalização tarifária. No subsetor rodoviário, o Programa de Concessões de Rodovias Federais foi lançado em 1993 (antes da promulgação da Lei das Concessões, ressalte-se). Já nos transportes aquaviários, a liberalização da navegação de longo curso ocorreu em 1991, e a Lei de Modernização dos Portos foi promulgada em 1993.

Todos esses processos foram impulsionados pelas ideias de redução da intervenção do Estado como forma de enfrentar a situação de crise fiscal e estagnação econômica no Brasil que eclodiu nos anos 1980 como resultado da crise do Estado nacional-desenvolvimentista. Tanto o PND quanto o Programa Federal de Desregulamentação enunciavam objetivos de reordenar a posição do Estado na economia, transferir à 
iniciativa privada atividades exploradas pelo setor público e descentralizar as ações administrativas para outras esferas de governo.

O setor de transportes, por ser historicamente caracterizado pela intervenção estatal, foi objeto das políticas liberalizantes. Contribuiu para isto o fato de, diferentemente de outros setores - como o de telecomunicações, por exemplo -, as prerrogativas do Estado não estarem fixadas na Constituição de 1988 (com exceção do transporte de mercadorias na navegação de cabotagem). Ao contrário, o artigo 175 da Carta Magna dispunha que o Poder Público podia prestar serviços públicos indiretamente, sob o regime de concessão ou permissão. Assim, por meio de leis ordinárias, medidas provisórias, decretos presidenciais e portarias ministeriais, o Executivo deu início aos processos de reforma no setor logo no começo dos anos 1990, sendo que a promulgação da Lei 8.987/1995 (Lei das Concessões) serviu de base para que as políticas desestatizantes deslanchassem.

Porém, como destacou Vogel, "mercados mais livres exigem mais regras" (1996; tradução livre). As reformas no setor de transportes, contudo, foram iniciadas sem preocupação regulatória e sob uma lógica fragmentada. Assim, a resultante do processo de desestatização foi um mosaico de atores privados e interesses cristalizados nas regras e organizações recém-configuradas.

Uma das grandes dificuldades das agências [de transportes] é você regular, você trabalhar em cima dos contratos de concessões já feitos onde muitos deles embutem grandes comandos, tanto na área ferroviária, quanto na área portuária e rodoviária. Você pega a própria condição de rentabilidade dos contratos rodoviários, você vê que hoje é completamente diferente. Você pega a concessão ferroviária feita pelo BNDES, a tônica era privatizar, ele não estava olhando muito como funciona o sistema [...] você começou a fazer uma privatização portuária onde, pela Lei 8.630/1993, a regra é a seguinte: se a iniciativa privada quer arrendar uma área, você arrenda [...] sem saber se é bom para a Companhia Docas, se está dentro do plano de desenvolvimento [do porto] (Ex-presidente do Geipot, entrevista ao autor em 26/7/2010).

Políticas públicas criam interesses e interesses formam o processo político (Lowi, 1964). Segundo Pierson (1993), as políticas públicas fornecem a base para padrões específicos de ação dos grupos de interesse, como discutido na seção intitulada A Abordagem Teórica deste artigo. 
A reforma portuária de 1993, ao permitir a privatização da operação e de áreas dentro dos portos públicos, criou nestes os Conselhos de Autoridade Portuária (CAPs) com competências regulatórias, constituídos por representantes do Poder Público, operadores portuários, trabalhadores e usuários dos serviços, cada um com um voto. Nesse arranjo, o setor privado acabou por possuir dois dos quatro votos do Conselho (dos operadores e dos usuários, constituídos pelos armadores, titulares das áreas privadas, exportadores, importadores e proprietários de mercadorias). Como argumentam Oliveira e Mattos (1998), é do interesse dos trabalhadores (cujo bloco representa mais um voto) entrar em acordo com os operadores em troca de melhores condições de trabalho e remuneração. Assim, o CAP tornou-se potencialmente uma instância de deliberação e regulação autônoma e de caráter corporativo, em que os interesses dos atores privados podem sobressair-se em relação aos do Poder Público. Conforme explica documento da Coordenação Geral de Transportes e Logística da Secretaria de Acompanhamento Econômico do Ministério da Fazenda (Nota Técnica no 16, de 16/2/2009:23):

Os terminais privados, por exemplo, podem estar interessados na minimização das tarifas portuárias, reduzindo os seus custos, bem como na restrição da oferta de áreas para arrendamento, reduzindo a presença de concorrentes. Os trabalhadores podem estar interessados em maior remuneração salarial e restrições à competição com agentes externos ao porto. Os usuários podem estar interessados em reduções do custo total dos serviços e em melhores condições de atendimento [...]. A forma como foi estruturada essa instituição [o CAP] pode resultar na necessidade de cooperação entre esses diversos agentes para o equacionamento de seus interesses.

Explica-se, logo, o interesse dos atores privados em manter essa organização regulatória autônoma e de forma descentralizada, sem a necessidade de supervisão ou interferência de uma agência nacional.

A Lei 8.630/1993 também autorizou os terminais de uso privativo a movimentar cargas de terceiros. Conforme essa lei, para a criação de um terminal de uso privativo é necessária apenas uma autorização do governo federal, sem necessidade de licitação. Isso criou uma situação singular, pois enquanto a exploração dos terminais de uso público depende de concessão precedida de licitação e está sujeita a uma série de regulamentações e fiscalização pela Autoridade Portuária, os terminais de uso privativo gozam de mais liberdade, com menos fiscaliza- 
ção e ônus (inclusive, sem a obrigação de utilizar a mão de obra intermediada pelos órgãos gestores de mão de obra). Daí o interesse da ABTP, associação que congrega as empresas detentoras ou administradoras de terminais de uso privativo, pela não inclusão dos portos na nova legislação que criaria a agência reguladora para o setor, como também sua ação em garantir intactas as disposições da Lei 8.630/1993 que regulam os contratos de arrendamento e de adesão.

Pierson (1993:600) também diz que, da mesma maneira que as instituições criam interesses que vão atuar para a manutenção das "regras do jogo", as políticas públicas podem alimentar mobilizações contrárias envolvendo formas de organização política que visam transformar a própria política em curso.

Foi o que se observou da atuação dos atores do subsetor de navegação marítima nas discussões do PL-1.615/1996 no Congresso. Como visto, as políticas de liberalização do subsetor ${ }^{19}$, que tinham o objetivo de aumentar a eficiência da atividade e expor os estaleiros brasileiros à concorrência internacional, tiveram como efeitos a diminuição da frota mercante nacional, com o expressivo aumento dos afretamentos de embarcações estrangeiras, e a contração da indústria naval brasileira ${ }^{20}$. Assim, a criação de uma agência nacional para o setor dizia respeito diretamente aos interesses dos atores vinculados à atividade da navegação: trabalhadores marítimos, armadores, donos de estaleiros e, sobretudo, o Comando da Marinha do Brasil. Esta, mediante a Diretoria de Portos e Costas (DPC), é responsável pelo controle da Marinha Mercante (pois é considerada o braço desarmado da Marinha de Guerra, cf. art. $4^{\circ}$ da Lei 6.880/1980). Ademais, cabe à Marinha a formação do pessoal marítimo, inclusive dos oficiais, e a regulação da praticagem ${ }^{21}$. Destarte, é do interesse da Marinha o país contar com uma armação própria, uma indústria naval forte e o controle do pessoal marítimo, e a criação de uma única agência de transportes englobando todos os subsetores, como propunha o Executivo inicialmente, ameaçava esses interesses. Contudo, por questões de hierarquia militar, o DPC não podia trabalhar explicitamente como ator interessado no processo de discussão da criação da ANT - o que não impediu que ele tivesse papel fundamental no processo, ao pôr em ação uma coalizão em prol da criação de uma agência específica dedicada ao transporte aquaviário.

Da Marinha [do Brasil] nós recebemos o seguinte: esta é a nossa visão para o transporte aquaviário brasileiro, a Marinha Mercante numa agência única. Agora, nós somos o Ministério de um governo [Ministé- 
rio da Defesa] e não cabe a nós... [mas] onde nós pudermos colocar avaliações técnicas que deem suporte a esta nossa visão, nós o faremos. (Presidente do Sindmar e do Conttmaf, entrevista ao autor em $15 / 9 / 2010)^{22}$.

Por isso, a coalizão em prol da criação de uma agência específica para o transporte aquaviário foi liderada por Severino Almeida Filho, oficial da Marinha Mercante e presidente da Conttmaf (confederação à qual estão filiados todos os sindicatos marítimos e as federações de sindicatos portuários), e vocalizada no Congresso (na Cesp do PL-1.615/1999) pela deputada Jandira Feghali (PCdoB/RJ). Ressalte-se que o objetivo da coalizão não era apenas criar uma agência reguladora para o transporte aquaviário, mas, sim, uma agência voltada para o desenvolvimento da Marinha Mercante nacional, nos moldes da antiga Sunamam, inclusive com sede no Rio de Janeiro, que agregaria as atividades do Fundo de Marinha Mercante como dito anteriormente.

A existência de uma agência própria vai forçar a existência de uma política e a necessidade de o governo se preocupar em fiscalizar, formular e traçar diretrizes para esse setor. Agora, se ela ficar na superintendência de um departamento de uma agência [geral de transportes] do Ministério [dos Transportes], adeus. Não teremos mais a possibilidade de discutirmos transporte aquaviário (Deputada Jandira Feghali, na reunião da Cesp do PL 1.615/1999, em 11/1/2000).

Os detentores de terminais privativos, representados pela ABTP, apesar de serem contrários à inclusão dos assuntos portuários no âmbito de uma agência reguladora de transportes, acabaram por se unir à coalizão liderada por Severino Almeida, sob a avaliação de que numa agência dedicada ao transporte aquaviário, ao contrário de uma agência única, teriam melhores condições de atuar em favor de seus interes$\operatorname{ses}^{23}$. Segundo o presidente da Conttmaf:

Eles [ABTP] se envolveram na defesa da atual Antaq para fugir do escopo que estava sendo preparado para eles dentro da proposta da [criação da] ANT [...]. Na realidade, eles tinham expectativa de não serem sequer citados [...]. Eu acho que o setor majoritariamente veio a defender a Antaq para se livrar do cabresto de uma agência única (Presidente do Sindmar e da Conttmaf, entrevista ao autor em 15/9/2010).

Esses fatos corroboram a proposição de Pierson (1993) de que a implementação de políticas públicas pode impulsionar novas formas de 
organização para modificar a política em curso, criando nichos e incentivos para que empreendedores políticos possam superar problemas de ação coletiva. No caso, a proposta de criação de uma única agência vinculada ao Ministério dos Transportes uniu atores que até então estiveram em lados opostos, como os trabalhadores portuários e o setor privado, ou os trabalhadores marítimos e os armadores.

Quanto à criação da ANTT, ressalte-se, os concessionários de ferrovias e rodovias tinham o interesse em garantir os contratos já firmados e as regras em vigor, sem alterações, o que vinha ao encontro da proposta do Executivo. Os trabalhadores ferroviários, por sua vez, estavam mais preocupados com o destino do pessoal da RFFSA do que com a criação da agência propriamente dita. Já os transportadores rodoviários de cargas e de passageiros viam a nova legislação como oportunidade para inserir dispositivos de modo a atender seus interesses específicos: restringir a entrada na atividade, no caso dos primeiros, ou para continuarem operando no mercado sem a necessidade de serem submetidos à licitação, no caso dos últimos ${ }^{24}$.

Para expressar o grau de cristalização de interesses em que se encontravam as instituições do setor federal de transportes no momento da discussão da criação das novas agências nacionais de transportes, pode-se citar a metáfora utilizada por ex-presidente do Geipot:

A gente sabia que o setor de transportes já estava privatizado e sem regras, onde cada um tinha o seu "puxadinho", vamos chamar assim [...]. A [proposta da] agência foi feita tipo "cavalaria em filme americano", que chega ao final para resolver o problema; [todavia] "o bandido já tinha matado o mocinho e casado com a mocinha" (Ex-presidente do Geipot, entrevista ao autor em 15/9/2010).

\section{CONCLUSÕES}

Este estudo de caso mostrou-se um instrumento para desvendar como atuam os mecanismos institucionais em processos de mudança regulatória e organizacional. Pôde-se perceber que a ordem e a sequência dos eventos no tempo são importantes para a análise dos processos políticos, como também que as instituições moldam o comportamento dos grupos.

No momento da criação da agência reguladora para o setor federal de transportes, os processos de desestatização, liberalização e descentra- 
lização já haviam ocorrido. A intenção do Poder Executivo ao encaminhar projeto de lei ao Congresso Nacional, portanto, era completar a reforma no setor com a delegação da autoridade regulatória do ministério setorial para uma agência autônoma.

Contudo, numa sequência de eventos, o momento em que as coisas acontecem afeta como elas ocorrem (Pierson, 1993). Por conseguinte, as instituições preexistentes permitiram a atuação do mecanismo de policy feedback de duas maneiras: (i) reforçando os interesses criados pelos arranjos institucionais preexistentes (caso do subsetor portuário, pós-reforma de 1993) e (ii) ativando reações contrárias de atores às regras do jogo implementadas no início dos anos de 1990 (caso da navegação marítima pós-liberalização). O "efeito reforço" levou atores a pressionar pela manutenção do arranjo existente; o "efeito contrarreação" induziu atores a construírem suas capacidades políticas, a fim de instituírem uma alternativa viável para as regras vigentes. Como a discussão da reestruturação do setor se deu na arena regulatória do Congresso, esses interesses tangenciaram-se, viabilizando uma coalizão que logrou impor suas preferências, ou seja, a criação de uma agência específica para o transporte aquaviário.

A abordagem teórica utilizada mostrou-se útil para explicar o fenômeno sob investigação de forma nuançada. Utilizando-se do process tracing, pôde-se compreender o enredamento dos processos causais, apreendendo os mecanismos em ação. Dessa maneira, verificaram-se as proposições teóricas apresentadas por Pierson $(1993 ; 2004 ; 2006)$ expostas na seção intitulada "O Processo Político", deste artigo.

A tipologia de Mahoney e Thelen (2010), por sua vez, auxiliou na explicação do tipo de mudança estudado. A mudança verificada no setor foi do tipo layering, com a introdução de novas regras e organizações sobre as preexistentes. Seguindo o modelo dos autores, as características das instituições, o contexto político e a estratégia dos atores ajudam a explicar o tipo de mudança analisado. Como foi considerado, atores importantes detinham poder de veto às intenções de se criar uma agência única aglutinando as modalidades de transportes - caso dos comandos militares. Desse modo, o Poder Executivo e sua coalizão no Congresso Nacional atuaram no sentido de buscar a reestruturação do setor sem confrontar completamente as instituições preexistentes, especialmente as do subsetor aquaviário. 
A pesquisa se enquadra no que George e Bennett (2004) chamam de building block studies. Nestes, a aplicação de frameworks para o estudo de casos concretos colabora para o refinamento das teorias, fornecendo "blocos" para a edificação e aperfeiçoamento das tipologias construídas com bases teóricas. A aplicação do modelo de Mahoney e Thelen (2010) impôs a avaliação da ação estratégica dos atores junto ao quadro institucional, permitindo incorporar os indivíduos na análise das mudanças e superar, assim, a dicotomia "estrutura versus agência" presente nas discussões institucionalistas.

Neste artigo as mudanças foram avaliadas sob um nível analítico setorial, portanto, menos abstrato. Isso implicou no relevo do papel dos atores e seus interesses em relação às estruturas para a explicação do fenômeno sob investigação. Ressalte-se, no entanto, que tais interesses não foram tomados como dados a priori. Ao contrário, partiu-se de uma base ontológica em que os interesses e a ação dos grupos são contextuais, isto é constituídos e moldados pelas instituições em vigor.

Segundo Knill e Lenschow (2001), muito do debate acadêmico e do desacordo sobre a presença e magnitude das mudanças institucionais podem ser atribuídas à atenção insuficiente dada para a escala de medição implícita das análises. Por isso, os autores argumentam que a percepção do tipo de mudança institucional (ou seja, se radical ou incremental) vai depender da perspectiva ou do grau de abstração adotado: se analisada in loco (em um baixo nível de abstração) ou a partir de uma perspectiva mais geral (isto é, à luz dos contextos macroinstitucionais). Por exemplo, de uma perspectiva individual (ou de grupos), a desestatização de empresas públicas significará uma mudança institucional radical; no entanto, sob uma perspectiva com maior grau de abstração, a mesma mudança pode estar alinhada com as tradições administrativas do país em questão e, desse modo, ser julgada como incremental.

Em suma, investigou-se aqui os nexos causais para compreender o processo político que resultou na reconfiguração institucional do setor federal de transportes, expressa na Lei 10.233, de 5 de junho de 2001. Seu objeto empírico foi a criação das agências reguladoras autônomas no setor; seu objeto teórico, os tipos e as dinâmicas de mudança institucional. Não obstante, como sugestão para pesquisas futuras, propõe-se a análise da evolução da trajetória do setor pós-implementação da citada lei, visando verificar o desenvolvimento das instituições no setor, se 
as mesmas se encontram em um caminho de autorreforço de suas trajetórias ou se sofreram alguma modificação fundamental, cabendo ao pesquisador explicar as causas e os processos inerentes às suas observações.

(Recebido para publicação em agosto de 2012)

(Reapresentado em agosto de 2013)

(Aprovado para publicação em outubro de 2013) 


\section{NOTAS}

1. As análises políticas sobre a criação das agências reguladoras no Brasil dos anos 1990 limitaram-se à criação das primeiras, quais sejam, para os setores de energia elétrica (Agência Nacional de Energia Elétrica - Aneel), petróleo (ANP) e telecomunicações (Anatel) (cf. Nunes et al., 2007).

2. Ressalte-se que esse conceito está compreendido na definição de instituições de North "as regras do jogo em uma sociedade ou, mais formalmente, os limites ou restrições criadas pelo homem que definem a interação social” (1990:3; tradução livre).

3. O mecanismo é caracterizado por processos de retroalimentação positiva que reforçam o desenvolvimento de uma instituição numa dada trajetória, fazendo com que os benefícios de permanência no caminho inicialmente trilhado, quando comparados às alternativas previamente possíveis, intensifiquem-se com o passar do tempo, aumentando os custos de reversão de uma trajetória já iniciada.

4. Como se sabe, a noção de path dependence foi desenvolvida originalmente por economistas que estudavam o tema do desenvolvimento tecnológico e depois foi utilizada por North (1990) para analisar as instituições econômicas. Pierson (2004), por sua vez, adaptou o conceito para as instituições políticas, ressaltando as características que diferenciam o mecanismo na política em relação à economia. São elas: a prevalência dos problemas da ação coletiva; a densidade e a interdependência das instituições políticas; a possibilidade do uso da autoridade para o reforço das assimetrias de poder; e o caráter complexo e opaco da política (cf. Pierson, 2004:30-40).

5. Segundo Capoccia e Kelemen (2007), as conjunturas críticas são períodos relativamente curtos de tempo durante os quais a influência das estruturas na ação política é relaxada, aumentando a probabilidade de que as escolhas dos atores que detêm o poder possam afetar o resultado de seu interesse.

6. Evocando Lowi (1964), "policies may create politics".

7. Segundo Pierson (1993), as políticas públicas podem conferir recursos substanciais para determinados grupos, como, por exemplo, subsídios financeiros (diretos e indiretos) ou infraestrutura organizacional, que são importantes na superação dos custos para a ação coletiva bem-sucedida.

8. Conforme Gerring (2007:173), o método de rastreamento de processos (process tracing) é semelhante ao trabalho de um detetive que, a partir do que precisa ser explicado, volta-se a descobrir os atores, suas motivações e ações, reconstituindo os processos que explicam o fenômeno sob investigação.

9. A Lei Complementar 97, de 9 de junho de 1999.

10. O Fundo de Marinha Mercante, principal instrumento de fomento do setor, é um fundo de natureza contábil, destinado a prover recursos para o desenvolvimento da Marinha Mercante Nacional, bem como para a construção de navios auxiliares da Marinha do Brasil (cf. Decreto-Lei n으 1.801, de 18 de agosto de 1980).

11. Conforme a Lei 8.630/1993, o CAP é um órgão deliberativo, consultivo e normativo, constituído pelas entidades diretamente envolvidas na atividade portuária, que atua na regulação das atividades e serviços realizados no porto.

12. Representados pela Associação Brasileira dos Terminais Portuários (ABTP), Federação Nacional dos Operadores Portuários (Fenop) e Confederação Nacional da Indús- 


\section{Alexandre de Ávila Gomide}

tria (CNI), estas integrantes da Comissão dos Portos (movimento empresarial comprometido com a implementação da reforma portuária).

13. Bandeiras de alguns países que aceitam o registro de embarcações estrangeiras para que os armadores possam daí retirar benefícios fiscais e/ou legais em comparação aos que teriam no seu país natal.

14. Nas palavras do presidente da Federação Nacional dos Estivadores, em audiência pública na Cesp, em 11/1/200: "nós não estamos satisfeitos [com a atual legislação dos portos]; mas, mal com ela, pior sem ela".

15. Depoimento da ex-deputada Telma de Souza, em entrevista ao autor em 3/1/2011.

16. A consulta ao sistema de prestação de contas eleitorais no Tribunal Superior Eleitoral mostra que entre os maiores doadores para a campanha de reeleição de Jandira Feghali à Câmara dos Deputados em 2002 encontram-se estaleiros, companhias de navegação e operadoras portuárias. Disponível em http:/ /www.tse.jus.br/eleicoes/eleicoes-anteriores/eleicoes-2002/contas-de-campanha-eleitoral-eleicoes-2002. Acesso em janeiro de 2011.

17. O Conit só foi formalmente instituído em agosto de 2008, pelo Decreto n⿳0 6.550, sendo que até março de 2010 o conselho tinha realizado apenas uma reunião, a de instalação, em 24/11/2009 (o decreto que dispõe sobre o Conit diz que o conselho deve se reunir ordinariamente a cada seis meses).

18. Por exemplo, do total de $\mathrm{R} \$ 7,3$ bilhões do orçamento de 2005 apenas $7 \%$ foram destinados ao modo hidroviário. Disponível em http://www.dnit.gov.br/institucional/relatorio-de-gestao/Relatorio\%20d\%20eGestaoã2005ãinterenet.pdf. Acesso em janeiro de 2011.

19. Além do processo de liberalização da navegação marítima ocorrido em 1991, a Lei 9.432/1997, que regulamentou a EC 7/1995, permitiu que empresas brasileiras de capital estrangeiro pudessem receber autorizações do governo brasileiro para atuar na atividade e estrangeiros puderam ser proprietários de empresas brasileiras de navegação (no passado, havia a necessidade de que 60\% do capital estivessem nas mãos de brasileiros natos). Ademais, permitiu-se que navios estrangeiros operassem a navegação de cabotagem, desde que afretados por empresas brasileiras (contudo, sob o processo denominado "circularização", em que as empresas nacionais consultam as outras sobre a disponibilidade de navios e, a partir daí, autoriza-se ou não o afretamento). Já a navegação de longo curso, ressalte-se, é aberta a qualquer tipo de embarcação, sem privilégios aos navios brasileiros (exceto para algumas poucas cargas ainda ditas reservadas).

20. Desde a abertura constitucional à cabotagem e à empresa estrangeira, em 1995, a atividade assistiu ao crescimento de nove vezes da bandeira estrangeira. Na navegação de longo curso, se em meados dos anos 1980 o país tinha a participação da bandeira brasileira para o transporte das cargas nacionais com percentual acima de $30 \%$, em 1999 essa relação pouco ultrapassava $2 \%$, excluindo o transporte de petróleo e derivados.

21. A praticagem é o serviço de auxílio oferecido aos navegantes, geralmente disponível em áreas que apresentem dificuldades ao tráfego livre e seguro de embarcações, em geral de grande porte. O prático é o indivíduo conhecedor dos acidentes hidrográficos e topográficos de áreas restritas marítimas, fluviais ou lacustres e que nelas conduz embarcações em segurança. 
22. Como indicado, oficiais da Marinha Mercante e o Comando da Marinha do Brasil manifestavam seu descontentamento com os resultados das políticas de liberalização e desregulação da navegação marítima, nomeadamente a redução da frota nacional e desmantelamento da indústria naval, recursos considerados indispensáveis para a segurança nacional.

23. Para Fiani (2002:49), a segmentação da atividade reguladora favorece a captura de uma agência a partir da constituição de policy networks restritas apenas a um determinado segmento do setor de transportes.

24. No texto final enviado ao Senado Federal foi incluído destaque aprovado pela Cesp que previa o instituto da autorização para o exercício da atividade de prestação de serviços de transporte rodoviário de cargas por conta de terceiros e mediante remuneração, vetado pelo presidente da República. Porém, na Medida Provisória 2.217-3, de 4 de setembro de 2001, que alterou a Lei 10.233/2001, o Executivo incluiu a necessidade de inscrição do transportador autônomo no recém-criado Registro Nacional de Transportadores Rodoviários de Carga. 


\section{REFERÊNCIAS BIBLIOGRÁFICAS}

BAUMGARTNER, Frank R. e JONES, Brian D. (1993), Agendas and Instability in American Politics. Chicago, University of Chicago Press.

CAPOCCIA, Giovanni e KELEMEN, R. Daniel. (2007), “The Study of Critical Junctures: Theory, Narrative, and Counterfactuals in Historical Institutionalism". World Politics, vol. 59, no 3, pp. 341-369.

COLLYER, Wesley O. (2008), Lei de Portos: O Conselho de Autoridade Portuária e a Busca da Eficiência. São Paulo, Aduaneiras.

FADDA, Eliane A. (1999), A Conta Serviços e a Contribuição de uma Marinha Mercante Nacional Forte. Monografia apresentada à Escola Superior de Guerra, Curso de Altos Estudos de Política e Estratégia. Escola Superior de Guerra, Rio de Janeiro.

FERRAZ, João C. et al. (2002), Estudo da Competitividade de Cadeias Integradas no Brasil: Impactos das Zonas de Livre Comércio. Núcleo de Economia Industrial e da Tecnologia. Cadeia: Indústria Naval. Nota Técnica Final.

FIANI, Ronaldo. (2002), “Aspectos do Modelo Regulatório Brasileiro: Uma Avaliação a partir dos Conceitos de Redes de Políticas e Herança Institucional". Anais do Seminário O Controle Externo da Regulação de Serviços Públicos. Brasília, TCU, pp. 37-52.

GEORGE, Alexander L. e BENNETT, Andrew. (2004), Case Studies and Theory Development in the Social Sciences. Cambridge, MIT Press.

GERRING, John. (2007), Case Study Research: Principles and Practices. Cambridge, Cambridge University Press.

GOMIDE, Alexandre de A. (2011), A Política das Reformas Institucionais no Brasil: A Reestruturação do Setor de Transportes. Tese de Doutorado em Administração Pública e Governo, EAESP/FGV, São Paulo.

HALL, Peter e TAYLOR, Rosemary. (2003), "As Três Versões do Neoinstitucionalismo". Lua Nova, no 58, pp. 193-223.

KNILL, Christoph e LENSCHOW, Andrea. (2001), “'Seek and Ye Shall Find!': Linking Different Perspectives on Institutional Change". Comparative Political Studies, vol. 34, no 2, pp. 187-215.

LOWI, Theodore. (1964), "American Business, Public Policy, Case-Studies, and Political Theory". World Politics, vol. 16, no 4, pp. 677-715.

MAHONEY, James e THELEN, Kathleen. (2010), "A Theory of Gradual Institutional Change", in J. Mahoney e K. Thelen (orgs.), Explaining Institutional Change: Ambiguity, Agency, and Power. Cambridge, Cambridge University Press, pp. 1-37.

MENARDI, Fabrício B. de Souza. (2004), Os Setores de Infraestrutura frente à Reforma do Estado no Brasil. Tese de Doutorado, Instituto de Filosofia e Ciências Humanas, Unicamp.

NORTH, Douglas. (1990), Institutions, Institutional Change, and Economic Performance. Cambridge, Cambridge University Press.

NUNES, Edson de Oliveira et al. (2007), Agências Reguladoras e Reforma do Estado no Brasil: Inovação e Continuidade no Sistema Político-Institucional. Rio de Janeiro, Garamond. 
OLIVEIRA, Gesner e MATTOS, Cesar. (1998), "Defesa da Concorrência nos Portos". RAE - Revista de Administração de Empresas, vol. 38, no 3, pp. 64-76.

PIERSON, Paul. (1993), "When Effect Becomes Cause: Policy Feedback and Political Change". World Politics, vol. 45, no 4, pp. 595-628.

. (2004), Politics in Time: History, Institutions, and Social Analysis. Princeton, Princeton University Press.

. (2006), "Public Policies as Institutions", in I. Shapiro; S. Skowronek, S. e D. Galvin (orgs.), Rethinking Political Institutions: The Art of the State. New York, New York University Press, pp. 114-134.

SCOTT, W. Richard. (2008), Institutions and Organizations: Ideas and Interests. (3a ed.). Thousand Oaks, CA, Sage Publications Inc.

THELEN, Kathleen. (1999), Historical Institutionalism in Comparative Politics. Annual Review of Political Science, vol. 2, pp. 369-404.

VELASCO JR., Licínio. (2005), A Política Pública de Privatização no Presidencialismo de Coalizão Brasileiro. Tese de doutorado, Instituto Universitário de Pesquisas do Rio de Janeiro (Iuperj), Rio de Janeiro.

VOGEL, Steven K. (1996), Freer Markets, More Rules: Regulatory Reform in Advanced Industrial Countries. Ithaca, Cornell University Press. 


\section{RESUMO}

Tipos e Dinâmicas de Mudança Institucional: As Agências Reguladoras de Transportes no Brasil

O artigo analisa o processo político que resultou na reconfiguração institucional do setor federal de transportes no Brasil, consubstanciada na Lei $\mathrm{n}^{\mathrm{o}}$ $10.233 / 2001$, que criou duas agências reguladoras autônomas vinculadas ao Ministério dos Transportes: a Agência Nacional de Transportes Terrestres e a Agência Nacional de Transportes Aquaviários. Utilizando-se da abordagem teórica do institucionalismo histórico da Ciência Política contemporânea e do método de rastreamento de processos, a análise mostra como a sequência dos eventos no tempo, as instituições e a estratégia dos atores delinearam um tipo específico de mudança institucional, caracterizado pela introdução de novas regras e organizações sobre as preexistentes.

Palavras-chave: mudança institucional; política regulatória; setor federal de transportes

\section{ABSTRACT}

Types and Dynamics of Institutional Change: Transportation Regulating Agencies in Brazil

This article offers an analysis of the political process that led to the institutional reconfiguration of the federal transport sector in Brazil, which came into force with Law $\mathrm{n}-10.233 / 2001$ creating two new regulating agencies attached to the Ministry of Transportation: the National Agency of Terrestrial Transportation and the National Agency of Waterway Transportation. Employing the theoretical approach of the historical institutionalism of contemporary Political Science and the process tracing method, the analysis shows how the sequence of events in time, institutions and actor strategies, outlined a specific pattern of institutional change, characterized by the introduction of new rules and organizations.

Keywords: institutional change; regulatory policy; federal transportation sector 


\section{RÉSUMÉ}

Types et Dynamiques de Changement Institutionnel: Les Agences de Régulation des Transports au Brésil

Dans cet article, on examine le processus politique qui a abouti au remaniement institutionnel du secteur fédéral des transports au Brésil, ratifié par la Loi no $10.233 / 2001$, créant deux agences régulatrices autonomes rattachées au Ministère des Transports: 1'Agence Nationale des Transports Terrestres et l'Agence Nationale des Transports sur eau. On s'est servi de l'approche théorique de l'institutionnalisme historique des sciences politiques contemporaines et de la méthode de repérage des processus; l'analyse montre comment la suíte des événements à travers le temps, les institutions et la stratégie des acteurs ont dessiné un type spécifique de changement institutionnel, marqué par l'introduction de nouvelles règles et d'organisations sur les précédentes.

Mots clés: changement institutionnel; politique de régulation; secteur fédéral des transports

\section{RESUMEN}

Tipos y Dinámicas de Cambio Institucional: Las Agencias Reguladoras de Transportes en Brasil

El artículo analiza el proceso político que resultó en la reconfiguración institucional del sector federal de transportes en Brasil, consubstanciada en la Ley $\mathrm{n}$ o 10.233/2001, que creó dos agencias reguladoras autónomas vinculadas al Ministerio de Transportes: la Agencia Nacional de Transportes Terrestres y la Agencia Nacional de Transportes Acuáticos. A partir de una apropiación teórica del institucionalismo histórico de la Ciencia Política contemporánea y del método de rastreo de procesos, el análisis demuestra cómo la secuencia de los eventos en el tiempo, las instituciones y la estrategia de los actores, delinearon un tipo específico de cambio institucional, caracterizado por la introducción de nuevas reglas y organizaciones que primaron sobre aquellas preexistentes.

Palabras clave: cambio institucional; política regulatoria; sector federal de transportes 